\title{
Mobilidade Urbana em Presidente Prudente: O caso do Bairro Ana Jacinta
}

\author{
Mariana Cristina da Silva Gomes \\ Graduada em Geografia - FCT/UNESP \\ Marcos Timóteo Rodrigues de Sousa \\ Pós-doutorado em Geografia Urbana - FCT/UNESP
}

\section{Resumo:}

A expansão da malha urbana está intrinsicamente ligada à valorização do preço da terra e a partir desta decorre uma produção do espaço urbano que é concentrado e disperso ao mesmo tempo. Este trabalho tem por objetivo demostrar a acessibilidade dos citadinos a partir dos deslocamentos diários e rotineiros do cotidiano, ou seja, as formas de mobilidade urbana. $\mathrm{O}$ resultado se desdobra, a partir dos questionários aplicados aos moradores do bairro Ana Jacinta, onde procuramos entender quais os meios de locomoção mais utilizados uma vez que a distancia é relativamente maior se comparado a outros bairros constantes nas áreas periféricas; Se existe acessibilidade dos moradores do bairro Ana Jacinta até o centro de Presidente Prudente/SP, bem como o acesso a outros bairros; e se é possível afirmar que a precarização dos meios de transporte coletivos e a imobilidade revelam práticas segregativas.

Palavras-chave: mobilidade urbana, deslocamentos, acessibilidade, cidades médias.

\section{Abstract:}

The expansion of the urban area is intrinsically linked to the appreciation of land prices and from this follows a production of urban space that is concentrated and dispersed at the same time. This study aims to demonstrate the accessibility of city dwellers from daily routine and displacement of everyday life, that is, forms of urban mobility. The result unfolds, from the questionnaires applied to residents of Ana Jacinta neighborhood where we try to understand what mobility means more used since the distance is relatively higher compared to other districts contained in the peripheral areas. If there is accessibility of the residents of Ana Jacinta neighborhood to the center of Presidente Prudente / SP , as well as access to other neighborhoods, and we can say that the precariousness of collective means of transport and immobility reveal segregating practices.

Keywords: urban mobility, displacement, accessibility, medium-sized cities . 


\section{MOBILIDADE URBANA}

Para Corrêa (2010), apoiando-se em Lefebvre, o espaço é mais do que um instrumento político de um indivíduo ou de um grupo, pois ele engloba esta concepção e a ultrapassa, por ser o lócus da reprodução das relações sociais de produção. Podemos dizer que determinada população ou grupo habita em uma localidade, circula, trabalha e consome em outras. Tal divisão do espaço que é, a um só tempo, econômica e social, explica as demandas por mobilidade espacial, sendo, ela própria, parte do processo de produção socioespacial das cidades.

um atributo associado às pessoas e aos bens; corresponde às diferentes respostas dadas por indivíduos e agentes econômicos às suas necessidades de deslocamento, consideradas as dimensões do espaço urbano e a complexidade das atividades nele desenvolvidas", ou, mais especificamente: "a mobilidade urbana é um atributo das cidades e se refere à facilidade de deslocamento de pessoas e bens no espaço urbano. Tais deslocamentos são feitos através de veículos, vias e toda a infraestrutura (vias, calçadas, etc.)... É o resultado da interação entre os deslocamentos de pessoas e bens com a cidade. (Ministério das Cidades, 2004c, p. 13).

Para analisar a mobilidade urbana e a produção socioespacial, é muito importante entender a dimensão do tempo. Para isso, destacamos Harvey (2008), quando ele cita Hareven (1982), que oferece base para a compreensão de tempo na sociedade moderna. O autor diz que o tempo da família, sob o capitalismo, é o tempo industrial, em que as pessoas são alocadas para o trabalho, para executar tarefas que propiciam a acumulação do capital. Por outro lado, a vida cotidiana que se realiza, além dos ditames do mundo do trabalho e, ao mesmo tempo, é parte dele, constitui-se, igualmente, em condicionante e 
expressão da mobilidade urbana, porque gera demandas e se estabelece segundo um conjunto de possibilidades.

Carreras (2005) ao tratar da dinâmica das cidades contemporâneas destaca, em suma, as mudanças no sistema produtivo, à expansão das empresas multinacionais, a hegemonia do capital financeiro, a lógica do capital globalizado, e a terceirização como resultante desse processo de capital flexível. O papel do consumo vem como novo reorganizador do sistema produtivo, pois o consumo de bens, de produtos e de serviços traz em si o debate de uma nova cultura entre o global e o local que se desdobram mudanças na sociedade, como por exemplo, a redução da família, a multiplicação de famílias unipessoais, e os novos conflitos sociais. O tempo e a flexibilização dos horários de trabalho, o aumento da velocidade das comunicações de todos os tipos e as características que demostram a complexidade da dinâmica da sociedade contemporânea. Assim, a mobilidade para todas as atividades citadas acima se estabelece em um espaço regulador da vida social.

Harvey (2008) cita Foucault, a respeito dos espaços de controle social, frisando que o espaço pode ser o que restringe ou que liberta razão pela qual pode ser também uma forma de segregar determinada população em um território. No nosso entendimento, a mobilidade urbana é, também, uma variável que pode interferir nas práticas segregativas, pois a população de baixa renda, que mora em bairros periféricos tem, muitas vezes, pouca acessibilidade às áreas mais centrais, via de regra, as mais equipadas das cidades brasileiras, o que pode se constituir em forma de segregação socioespacial.

A pesquisa realizada pelo CEMESPP (2009), que se volta ao estudo de cidades médias no Estado de São Paulo, mostra que as condições para acessar os locais de trabalho, consumo, lazer, saúde e educação estão intimamente ligadas aos custos de transportes, pois estes determinam as possibilidades de um grupo de pessoas se inserirem, usufruir e participar dos ambientes que estão dispostos na cidade. Nota-se que muitas cidades expressam, em suas estruturas espaciais, estratégias de afastamento socioespacial reveladas por separações que resultam do movimento em direção às periferias urbanas tanto quanto o reforçam, numa forte hierarquização das novas áreas residenciais e numa concentração de comércios e serviços em determinadas áreas da cidade, como parte do processo de descentralização que é, também, marcado por segmentações socioespaciais.

Nas últimas décadas, a localização das habitações na cidade adquiriu importância ainda mais estratégica, em função da tendência de dispersão urbana e de conformação de uma 
urbanização cada vez mais difusa, o que envolve problemas de mobilidade e acessibilidade concernentes à distância e aos meios de transportes, sobretudo em cidades como as brasileiras em que as condições de transporte coletivo ou individual não estão dispostos de modo equitativo, nem social nem espacialmente A tendência ao afastamento espacial das famílias de baixa renda tem implicado em precarização das condições de vida decorrentes da quantidade e qualidade dos meios de consumo coletivos disponíveis (infraestruturas, equipamentos e serviços urbanos), mas também favorece a ocorrência de relações sociais cada vez mais marcadas por conflitos, aos quais podem se associar determinadas práticas de violência (KOWARICK, 2009), nas grandes cidades, que podem, no caso das cidades médias, gerar representações e práticas espaciais que revelam insegurança urbana (SPOSITO e GOES, 2013)

Considerando-se estes pontos, é fundamental destacar o que é particular à nossa realidade urbana, para destacar, em seguida, as especificidades das cidades médias e, de modo singular, nosso foco de análise, que é Presidente Prudente. Para ter base para compreender os fundamentos de nossa formação socioespacial (SANTOS, 1976) é importante destacar alguns pontos. Comparativamente às cidades europeias, para tomar como referência um contraponto no mundo ocidental, as brasileiras têm duas características que são particulares e têm papel forte na lógica de estruturação de seus espaços. A primeira é relativa às históricas desigualdades socioespaciais, que marcam nossa sociedade e, portanto, nossa realidade urbana. Ainda que tenha havido, desde 2002, aumento do poder aquisitivo dos mais pobres, isso não se refletiu, ainda, em diminuição, ao nível desejado, das disparidades socioeconômicas. Além disso, mesmo que tenha havido melhoria, o aquecimento da economia, na última década, tornou mais cara a vida nas cidades, em função das dinâmicas de valorização imobiliária, o que orientou novo movimento de ampliação das desigualdades espaciais. Este processo tem forte rebatimento sobre a lógica de circulação urbana, alterando as relações entre acessibilidade e mobilidade, porque se intensificou o afastamento espacial dos mais pobres, em função dos custos progressivamente mais caros do espaço urbano.

Em segundo lugar e em decorrência do primeiro ponto, houve maior acesso ao transporte individual (carros e motocicletas), em função da melhoria de poder aquisitivo e da ampliação da oferta de crédito. Este movimento reforça, de um lado, a tendência à supervalorização destes veículos, no imaginário social, como uma mercadoria que se 
associa à distinção social e, de outro, ajuda os trabalhadores dos estratos mais baixos da pirâmide social a solucionar o problema do transporte, visto que o sistema coletivo de circulação urbana não é suficiente, em termos de cobertura espacial; não é eficaz, no que se refere ao tempo necessário ao deslocamento; nem oferece conforto, no que tange à infraestrutura de apoio (terminais, pontos de ônibus, sinalização etc.) e aos veículos que garantem os deslocamentos (nas cidades médias, preponderantemente ônibus, que não são climatizados, num país de verão longo; e, por fim, não estão adequados, na frequência e tamanho, para o número de passageiros a serem transportados).

Considerando-se estes níveis de determinação, há forte impacto de um conjunto amplo de fatores sobre a mobilidade nos espaços urbanos, entendida a mobilidade como a capacidade de um indivíduo deslocar-se e o uso que esse indivíduo faz dessa capacidade.

\section{MOBILIDADE DA POPULAÇÃO DE ÁREAS PERIFÉRICAS}

No capítulo abaixo estudamos a mobilidade da população de uma área periférica, analisamos o bairro do Ana Jacinta. Foram distribuídos 50 formulários de pesquisa no bairro. Além dos formulários, tiramos fotos, circulamos pelos bairros, andamos de ônibus e entrevistamos os moradores. Os trabalhos de campo neste bairro foram realizados conjuntamente com as visitas aos órgãos públicos e empresas privadas do ramo de transporte coletivo.

A pesquisa no município de Presidente Prudente também contou com a utilização de enquetes realizadas no centro da cidade, o objetivo foi levantar informações para refletir sobre a mobilidade dos frequentadores da área central. As 330 enquetes foram realizadas entre os dias 11 de setembro de 2013 e 05 de outubro de 2013 e foram realizadas no calçadão. Estas informações tiveram como objetivo entender com que frequência os citadinos se deslocam até o centro (a frequentação do centro pelos citadinos) em suas diversas formas de acesso e o uso daquela área e possibilitou, através da análise e representação gráfica, exibir o modal de transporte utilizado por eles para acessar o centro da cidade, representado pelo gráfico 1 . 
Gráfico 1: Bairro Ana Jacinta: Frequentação do centro por modal de transporte, 2013.

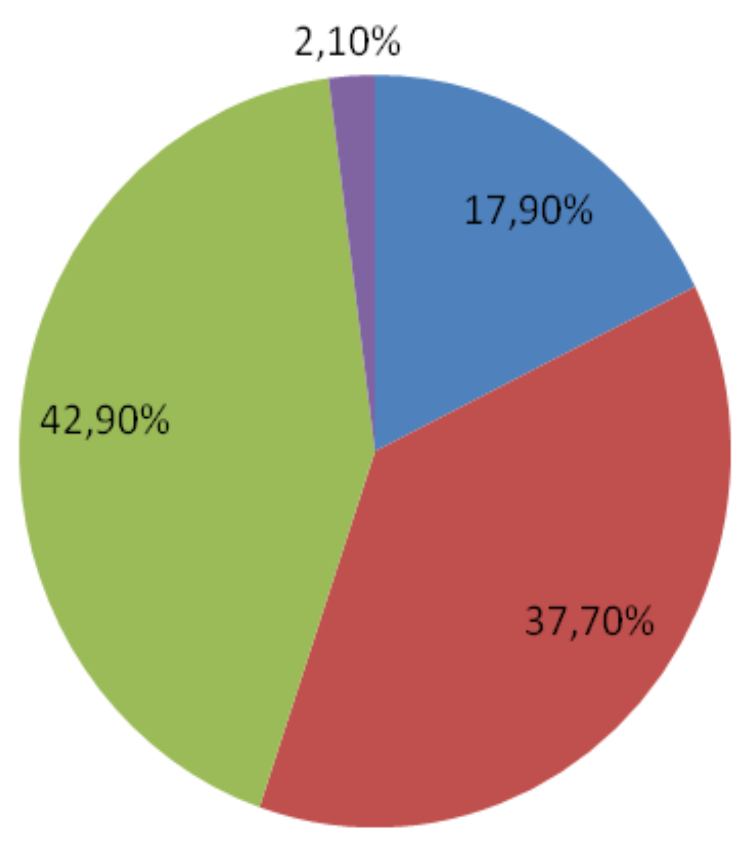

a pé: $17,9 \%$

transporte coletivo: $37,7 \%$

condução própria: $42,9 \%$

outras respostas: $2,1 \%$

Fonte: Pesquisa de campo. 2013

Organização: Marcos T. R. Sousa

A porcentagem dos citadinos que se deslocam para o centro através de condução particular representa 42,9\% da amostragem. Por outro lado, 37,7\% utilizam o transporte coletivo. A área central de Presidente Prudente apresenta uma maior quantidade de linhas de ônibus, a relativa densidade residencial no seu entorno, ressalta o poder de centralidade dos espaços comerciais tradicionais bem como seu caráter de concentração tornando essa área atrativa para atividades de compras e lazer destes moradores.

Em relação à frequentação ao centro, o indicador origens e destinos desta área revela que 75,2\% da amostra reside em Presidente Prudente, representado pelos moradores da área central e o bairro Ana Jacinta, que dista aproximadamente 10,2 km. A frequentação do centro pelos moradores dos municípios vizinhos, $21,3 \%$ da amostra, é representada pelos moradores de Álvares Machado e Presidente Bernardes, cidades mais notificadas e pertencentes à região de influência de Presidente Prudente. 
As condições dos meios de transportes públicos cooperam para que a maioria dos citadinos valorizem os meios de condução própria (Gráfico 1), preferência essa que resulta em desconforto e superlotação das vias em horários de pico.

Podemos, assim como fez Cruz (2013) pontuar alguns problemas enfrentados pelos que utilizam do transporte público coletivo para se locomover e ter acesso aos espaços da cidade. Primeiramente há uma má distribuição dos pontos de ônibus, ou até mesmo a inexistência destes. O tempo de espera do ônibus também é um agravante. Não existem meios de informação para saber os horários de ônibus, a precariedade dos ônibus também deixa a desejar, uma cidade cujo conforto térmico nas épocas mais quentes chega aos extremos, os ônibus não contam com nenhum sistema minimizador desta situação. $O$ estado de conservação, o tempo do trajeto e o trajeto da linha além do custo da passagem são outros fatores que influenciam a utilização do transporte público coletivo.

Vale salientar que Silveira e Cocco (2011) fazem uma análise dos problemas de transporte coletivo público na cidade de Presidente Prudente-SP, onde afirmam que os micro-ônibus do próprio sistema de transporte público são utilizados em linhas e horários de grande demanda, gerando uma lotação e um desconforto aos usuários. Estes fatos se constituem como uma forma de redução de custos encontrada pela empresa, na qual os micro-ônibus consomem menor quantidade de combustível e tem um número menor de assentos, o que promove alta rentabilidade para a empresa.

Entretanto, de acordo com as empresas operadoras (TCPP e Pruden Express), esses veículos apresentam um desempenho ruim, pois acumulam desgastes mecânicos nos horários de superlotação, devido ao excesso de peso e à deficiência na infraestrutura viária. Alguns micro-ônibus deixam de parar nos pontos de embarques por conta da superlotação.

A pesquisa mais específica sobre a mobilidade urbana em áreas periféricas em Presidente Prudente foi realizada no bairro Ana Jacinta. A figura 1 e o gráfico 2 exibem que as linhas de ônibus deslocam os passageiros do bairro em direção ao centro da cidade. 


\section{Figura 1: Linhas de ônibus no bairro Ana Jacinta - Presidente Prudente}

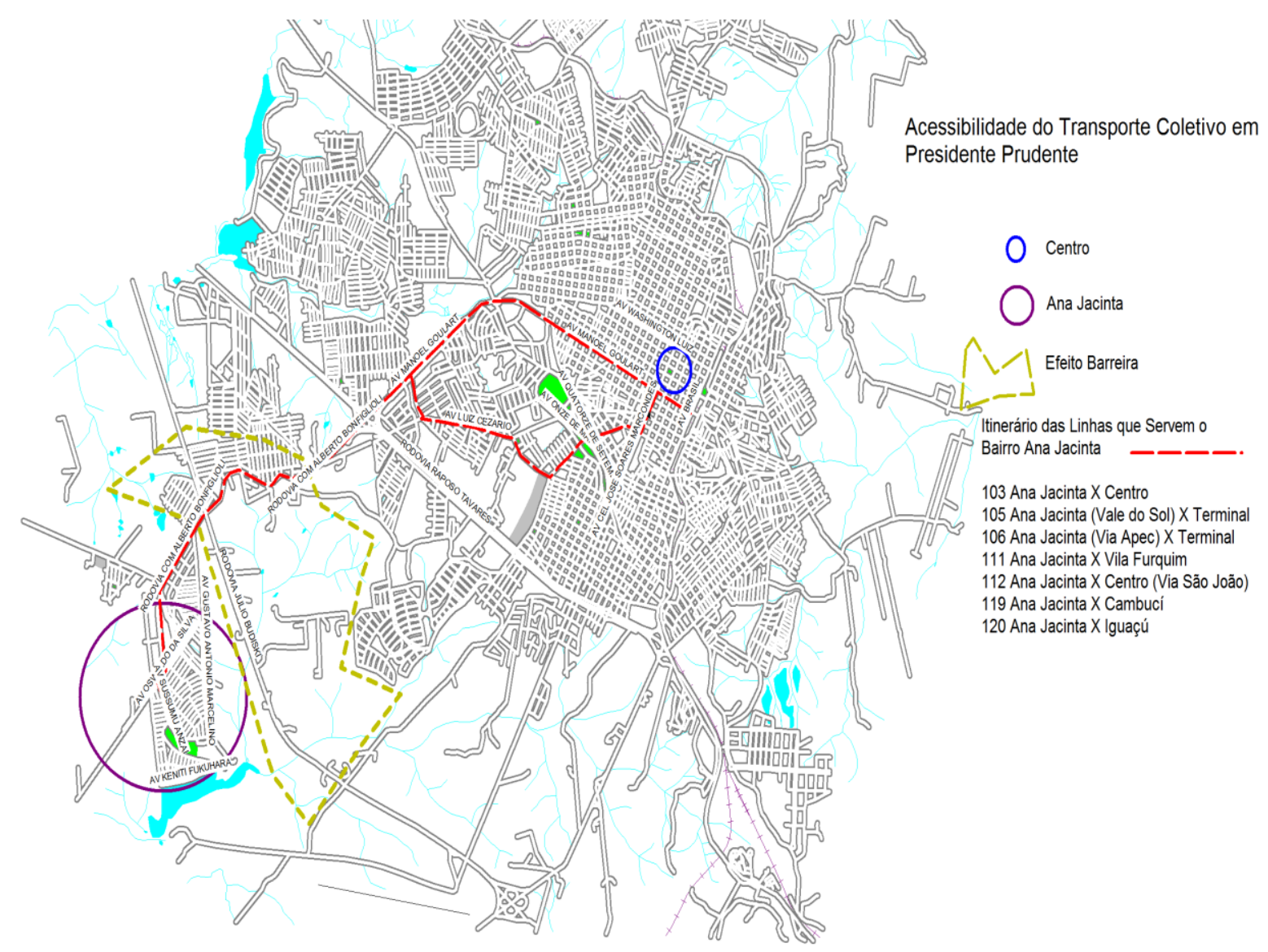

Fonte: SEMAV, 2014.

Organização: Marcos Timóteo Rodrigues de Sousa.

As linhas de ônibus utilizadas no itinerário que atende a população residente no bairro Ana Jacinta até o Centro são os ônibus: 103 - Ana Jacinta x Centro; 105 - Ana Jacinta (Vale do Sol x Terminal); 106 - Ana Jacinta (Via Apec) x Terminal; 111 - Ana Jacinta x Vila Furquim; 112 - Ana Jacinta x Centro (Via São João); 119 - Ana Jacinta x Cambuci; 120 - Ana Jacinta x Iguaçú.

Segundo os moradores do bairro Ana Jacinta as linhas mais utilizadas são as apontadas no Gráfico 2 abaixo. 
Gráfico 2: Linha de ônibus mais utilizada pelos moradores do bairro Ana Jacinta, 2014

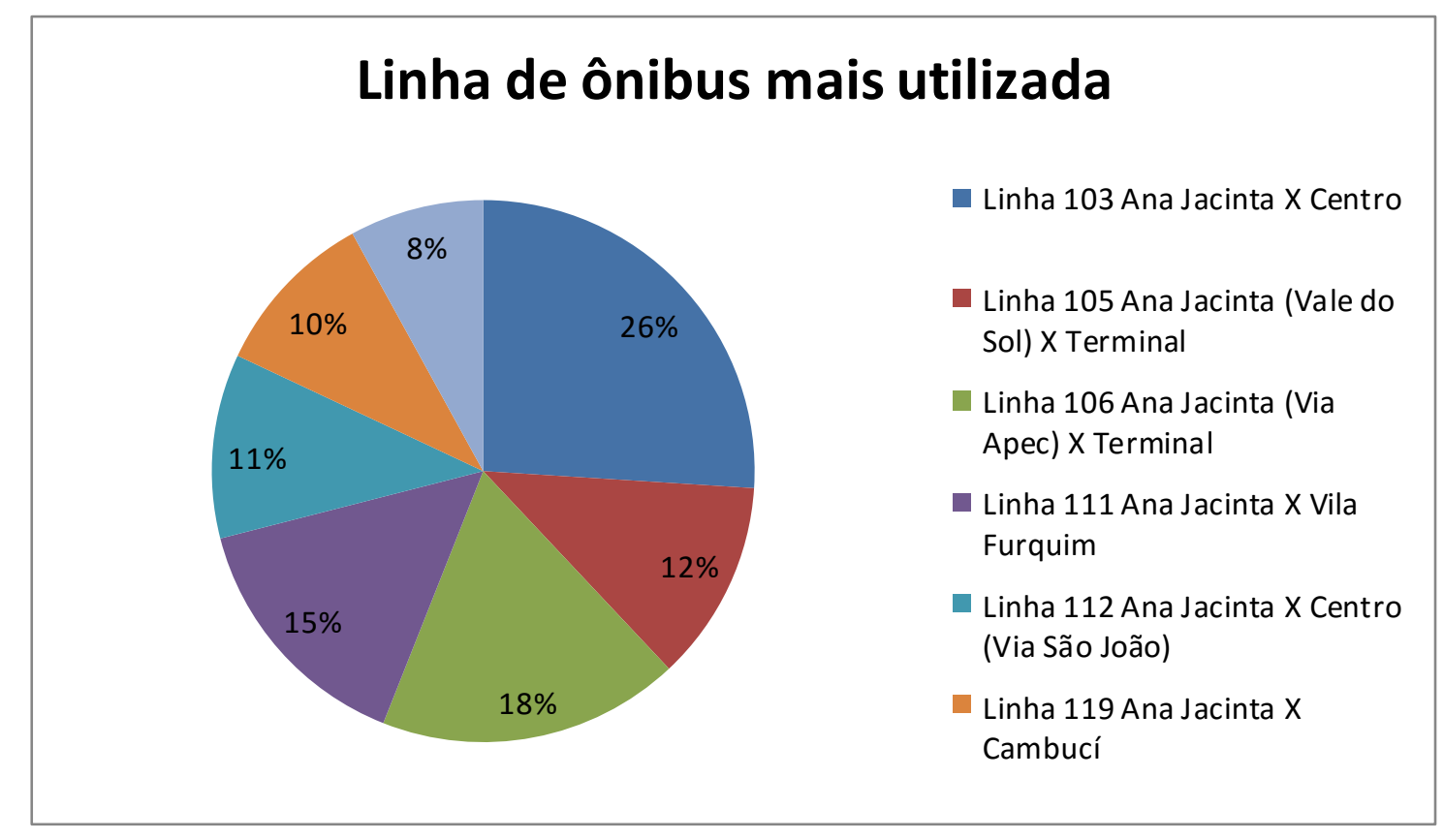

Fonte: Pesquisa de Campo dos Autores, 2014.

Questionados sobre as formas de condução para o acesso da escola e trabalho, tivemos os seguintes gráficos:

Gráfico 3: Modo de transporte utilizado para acessar o trabalho: Bairro Ana Jacinta (Presidente Prudente)

\section{Modo de Transporte para acessar o trabalho}

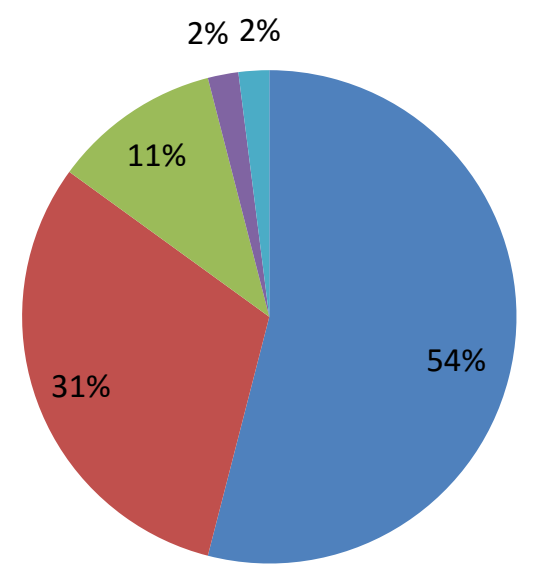

Ônibus

- Automóvel

Motocicleta

A Pé

Bicicleta 
Fonte: Pesquisa de Campo dos Autores, 2014

Gráfico 4: Modo de transporte utilizado para acessar a escola: Bairro Ana Jacinta (Presidente Prudente)

\section{Modo de transporte para acessar a escola}

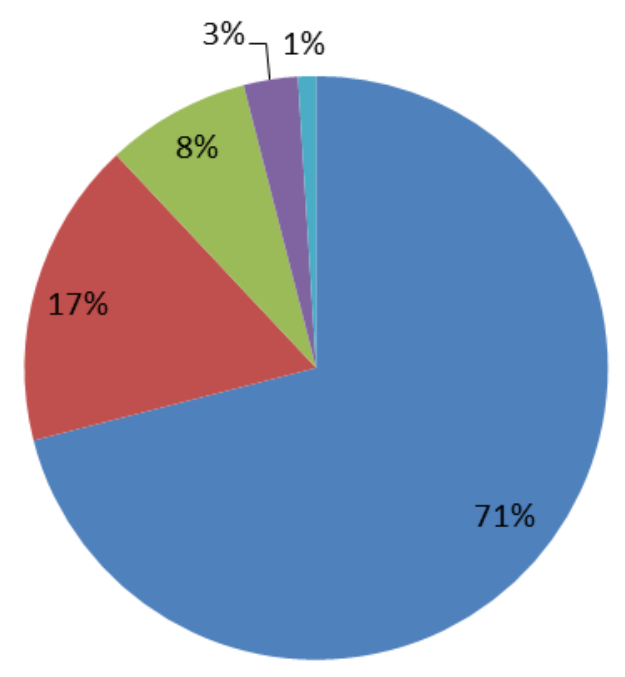

—ônibus

Automóvel

Motocicleta

A pé

Bicicleta

Fonte: Pesquisa de Campo dos Autores, 2014.

Os gráficos 3 e 4 mostram que o transporte coletivo é o mais utilizado para acessar as áreas onde se localizam tanto o trabalho quanto a escola. Nas 50 enquetes realizadas no bairro, os deslocamentos ao trabalho quase equivalem ao transporte coletivo e individual. Um pouco mais da metade, com $54 \%$, utilizam o ônibus para trabalhar, fato diferenciado em relação ao acesso á escola, pois, $71 \%$ utilizam os coletivos para os estudos.

A utilização das motocicletas, um fenômeno nacional, pouco mencionada nesta enquete, em muitos casos utilizados para o trabalho, isso se deve aos baixos custos com combustível. Em relação aos deslocamentos em direção aos estudos a menor quantidade de utilização do automóvel em relação ao trabalho se deve, segundo conversa com moradores, aos baixos custos de passagem e fluidez do trânsito no período noturno.

Questionados sobre o local do trabalho, estudos e tempo de deslocamento no trânsito obtivemos os seguintes dados: 
Gráfico 5: Local do trabalho dos moradores do Bairro Ana Jacinta (Presidente Prudente)

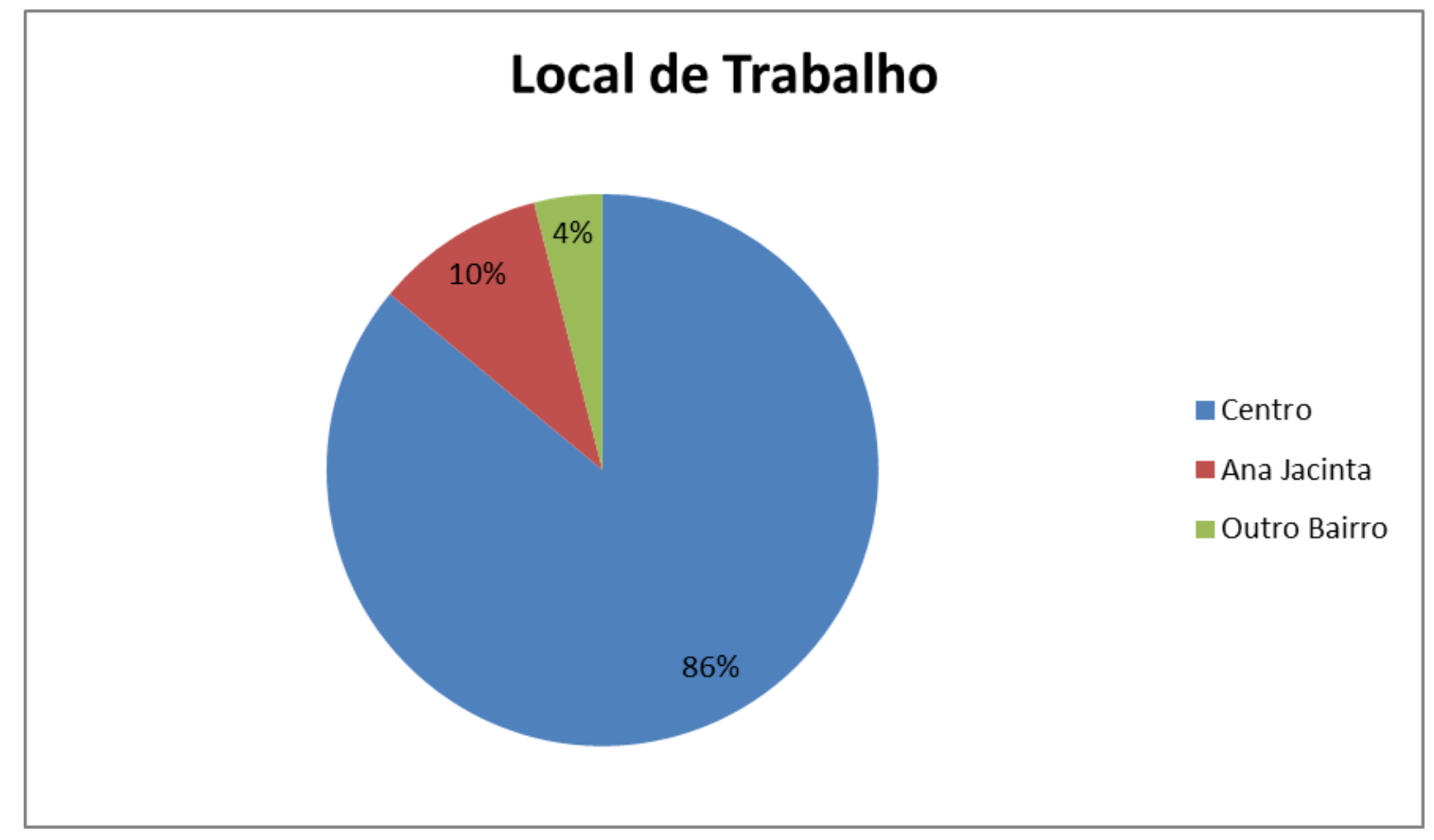

Fonte: Pesquisa de Campo dos Autores, 2014.

Gráfico 6: Local de estudos dos moradores do Bairro Ana Jacinta (Presidente Prudente)

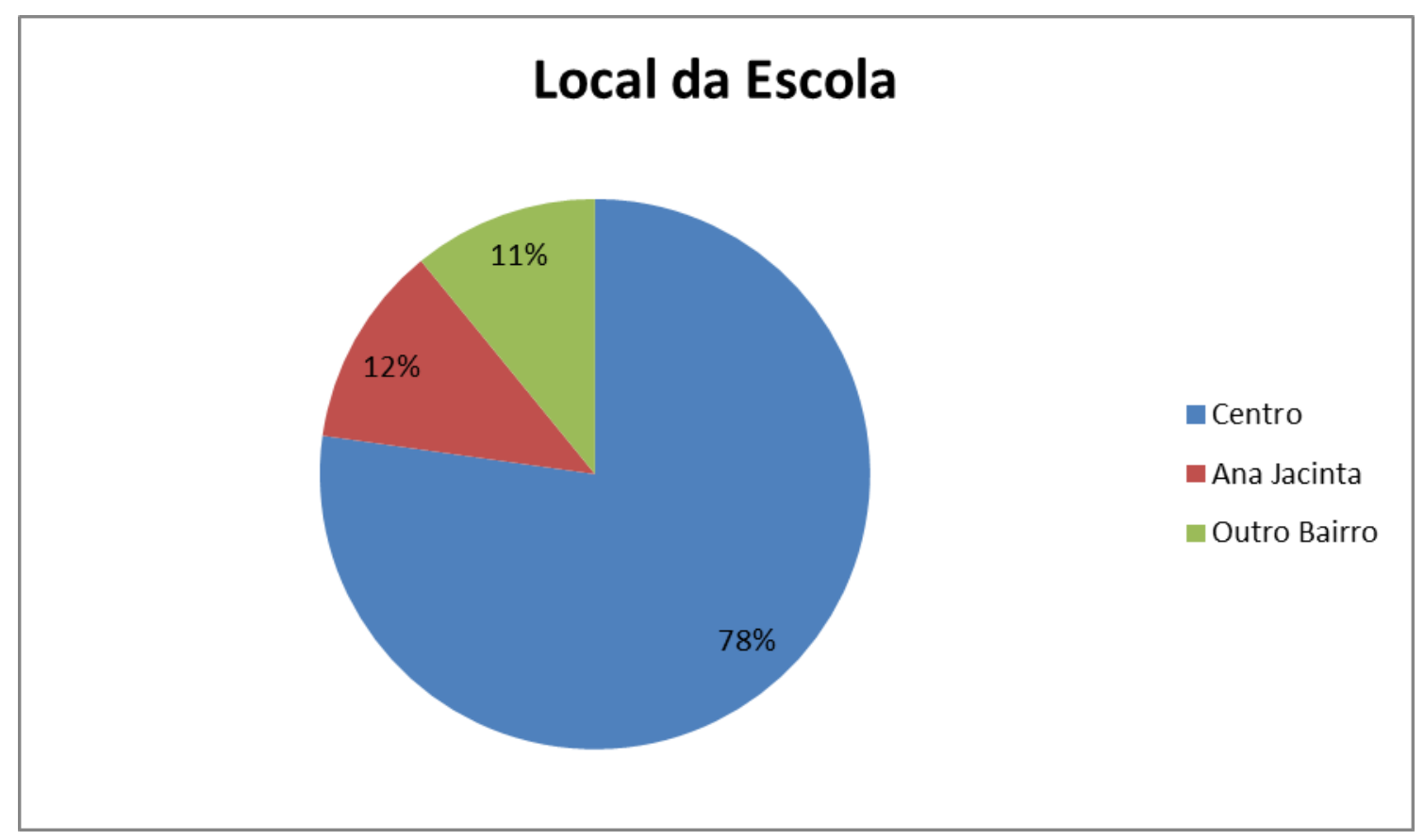

Fonte: Pesquisa de Campo dos Autores, 2014 
Gráfico 7: Tempo para acessar o centro da cidade

\section{Tempo para acessar o centro da cidade}

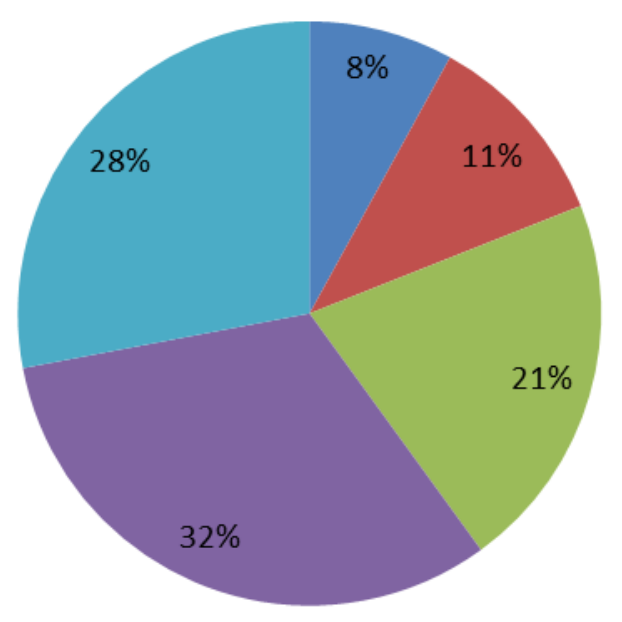

- 10 minutos

- 20 minutos

- 30 minutos

- 40 minutos

mais de 40 minutos

Fonte: Pesquisa de Campo dos Autores, 2014.

A partir da análise deste podemos afirmar que os gráficos 5 e 6 dão uma noção amostral de locais de trabalho e estudos, a grande maioria, $86 \%$ e $78 \%$, trabalham e estudam respectivamente no centro da cidade de Prudente. O gráfico 7 mostra que $32 \%$ dos moradores gastam cerca de 40 minutos para acessar o centro, este tempo sempre em relação aos horários de pico, para ir retornar ao trabalho e á escola. A escolha do bairro Ana Jacinta, para a realização da pesquisa sobre bairros periféricos, deve-se também à distância em relação à área central, ao efeito barreira e as enquetes que foram realizadas no centro, nas quais o bairro foi muito citado. Diferentemente de São Carlos, a cidade de Prudente não exibe uma barreira geomorfológica tão notória quanto à "serrinha" do bairro Cidade Aracy em São Carlos.

Nas questões sobre "Quantas viagens realizadas por dia para acessar outras localidades", "Os motivos das dificuldades para acessar outros bairros da cidade" e "Locais da cidade que pretende visitar, mas não há possibilidades (Imobilidade)" obtivemos a partir das respostas dos moradores do bairro Ana Jacinta os seguintes gráficos: 
Gráfico 8: Mobilidade urbana dos moradores do bairro Ana Jacinta - Presidente Prudente.

\section{Quantas viagens realizadas por dia para acessar outras localidades}

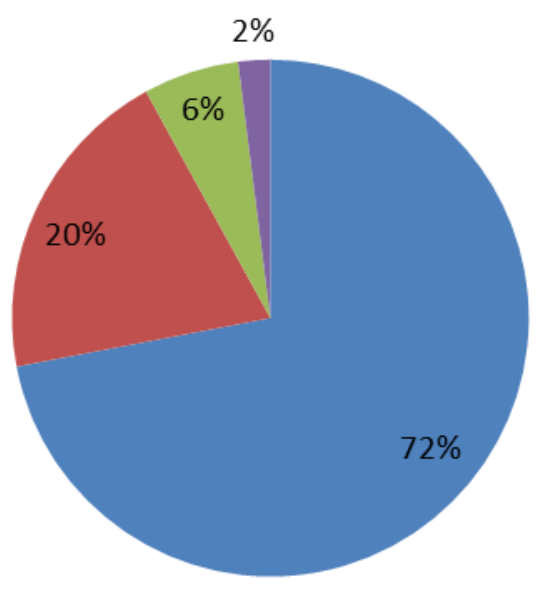

- 2 Viagens

4 Viagens

6 Viagens

Mais de 6 Viagens

Fonte: Pesquisa de Campo dos Autores, 2014

Gráfico 9: Motivo das dificuldades para acessar outros bairros da cidade

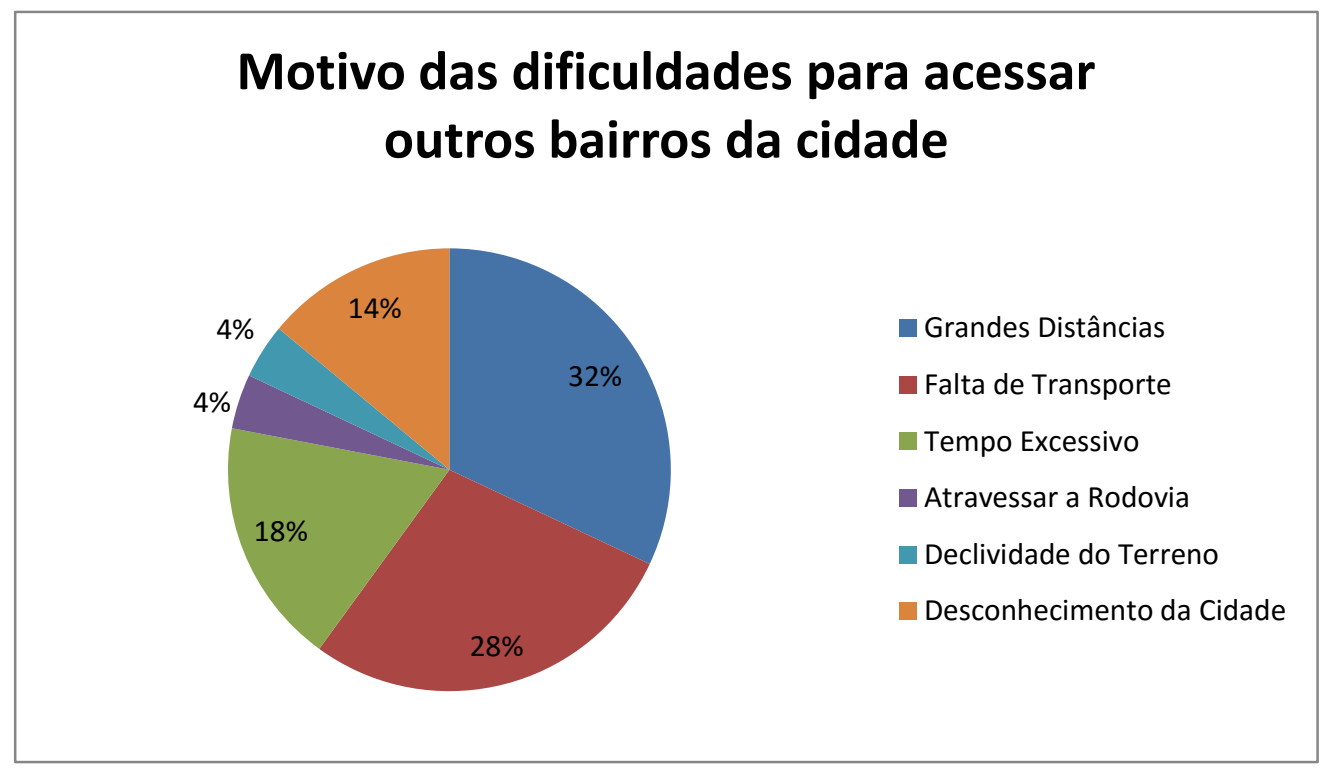

Fonte: Pesquisa de Campo dos Autores, 2014 
Gráfico 10: Locais da cidade que pretende visitar, mas não há possibilidades (Imobilidade)

\section{Locais da cidade que pretende visitar, mas não há possibilidades (Imobilidade)}

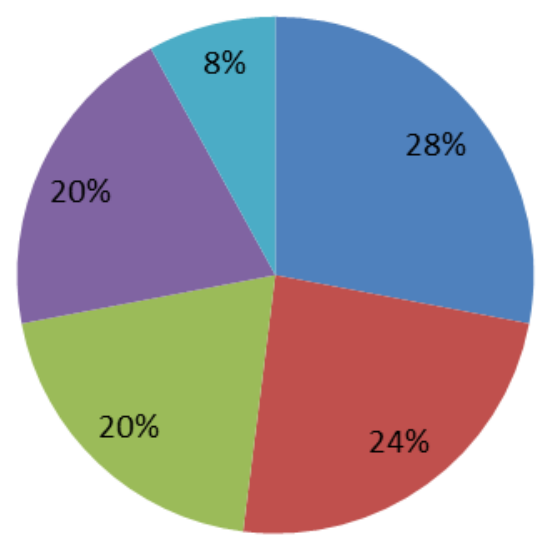

- Parque do Povo

- Cidade da Criança

- PrudenShopping

- Centro

Outros

Fonte: Pesquisa de Campo dos Autores, 2014.

O gráfico 8 comprova a tese de que a maioria das pessoas que moram muito distante das áreas centrais se movimenta pela cidade executando uma mobilidade pendular (casa trabalho - casa). Tal atividade cotidiana impossibilita a realização das demais viagens, esta pouca geração de viagens gera uma baixa mobilidade para os habitantes do bairro Ana Jacinta em Presidente Prudente e um grau de apropriação do conjunto da cidade menor, pois as possibilidades de fazer maior número de deslocamentos por dia e ir a outros bairros é menor.

Os gráficos 9 e 10 nos mostram as dificuldades que proporcionaram a baixa mobilidade dos moradores do bairro. As grandes distâncias e a falta de transporte colaboraram para inibirem as pessoas de acessar outras localidades. No caso do bairro Ana Jacinta, as 50 enquetes apontam o Parque do Povo e a Cidade da Criança como os locais como maior desejo de viagem.

As dificuldades de locomoção dos moradores das áreas periféricas mais distantes ao centro a partir do uso do transporte urbano coletivo, que deveriam por sua vez amenizar tais problemáticas, acabam por barrar o acesso á cidade a partir da imobilidade, ou seja, o não acesso. 


\section{REFERÊNCIA BIBLIOGRÁFICA}

ANDRADE, Thompson A., SERRA, Rodrigo V. O recente desempenho das cidades médias no crescimento populacional urbano brasileiro. Rio de Janeiro, Texto para discussão n. 554 IPEA, 1998.

ANTICO, Cláudia. Mobilidade populacional diária na Região Metropolitana de São Paulo. Trabalho apresentado no II Encontro Nacional sobre Migração, Ouro Preto, EBEP, 1999.

BAUDRILLARD, Jean. A sociedade de consumo. Lisboa: Edições 70, 2005.

BORGES, W. A., ROCHA, M. M. A compreensão do processo de periferização urbana no Brasil por meio da mobilidade centrada no trabalho. Rio Claro, Revista de Geografia, v29, n. 3, 2004, p.383-400.

CASTELLS, Manuel. A questão urbana. São Paulo: Paz e terra, 2000.

COCCO, R.G. SILVEIRA, M. R. Transporte público coletivo: acessibilidade e crise nas cidades do interior paulista. In: SILVEIRA, M. R. (org). Circulação, Transporte e Logística: diferentes perspectivas. São Paulo: Ed. Outras Expressões, 2011. p. 553-580.

CORRÊA, Roberto L. O espaço urbano. São Paulo: Ática, 1989.

CRUZ, D. A. M. O. Problemas do transporte público coletivo em Presidente Prudente/SP. Revista Percurso - NEMO, Maringá, v.5, n. 1, 2013, p. 179- 196.

DEL RIO, Vicente. Introdução ao desenho urbano no processo do planejamento. São Paulo: Pini, 1990.

FERRARI, Celson. Dicionário de urbanismo. São Paulo: Disal, 2004.

FERRAZ, Antônio Clovis Pinto, TORRES, Isaac Guillermo Espinosa. Transporte Público Urbano. São Carlos: RIMA 2004.

FERRAZ, Antonio Clovis Pinto. Sobre a eficiência e a eficácia do transporte público nas cidades médias e pequenas. Escola de Engenharia de São Carlos, USP. São Carlos, 1990

FERREIRA, Marcos Antônio Garcia, SILVA Júnior, Sílvio Barbosa da. Rodovias em áreas urbanizadas e seus impactos na percepção dos pedestres. Uberlândia, UFU, Revista Sociedade e Natureza, 20, jun.2008, p.221-237. 
LEFEBVRE, Henri. A revolução urbana. Belo Horizonte: UFMG, 1999.

LEFEBVRE, Henri. O direito e cidade. São Paulo: Centauro, 2001.

LENCIONI, Sandra. Redes, coesão e fragmentação do território metropolitano. In: Anais do Coloquio Internacional de Geocrítica, XI, Buenos Aires, 2010.

LIMA, José Júlio. Segregação Socioespacial e Forma Urbana: Belém no final dos anos 90. In: Brasil Urbano. Rio de Janeiro, Mauad, 2004, pg. 147 - 169.

LIMA, R. S. Expansão Urbana e Acessibilidade: $O$ caso das cidades médias brasileiras. São Carlos. Dissertação de Mestrado. EESC USP, 1998.

LOJKINE, Jean. O estado capitalista e a questão urbana. São Paulo: Martins Fontes, 1981.

LYNCH, Kevin. A Imagem da Cidade. Tradução Jéferson Luiz Camargo. São Paulo: Martins Fontes, 1997.

MOUETTE, Dominique. Os pedestres e o efeito barreira. São Paulo, Tese de Doutorado, POLI/USP, 1998.

MOURA, Rosa; ULTRAMARI, Clóvis. Periferia Urbana. São Paulo: Brasiliense, 1996.

NTU, Associação Nacional das Empresas de Transportes Urbanos. Avaliação Comparativa das Modalidades de Transporte Público Urbano. Curitiba, Jaime Lerner Arquitetos Associados, 2009.

RIBEIRO, Luiz César de Queiroz; LAGO, Luciana Corrêa. Reestruturação nas grandes cidades brasileiras: o modelo centro/periferia em questão. XV Encontro Anual da ANPOCS, Caxambu, MG, 1991.

SANTOS, Milton. A urbanização brasileira. São Paulo: Editora Hucitec, 1996.

. Por uma economia política da cidade. São Paulo: Hucitec e Educ, 1994.

SOUSA, Marcos Timóteo Rodrigues de; SPOSITO, Maria Encarnação Beltrão. Mobilité et accessibilité dans l'espace urbain: le cas de la ville de Sao Carlos, État de Sao Paulo, BRÉSIL, Avignon, France, Revue Territoire en Mouvement, 2013 (processo de avaliação). 
SOUSA, Marcos Timóteo Rodrigues de; CASTRO, André Felipe Vilas de. Mobilidade urbana e shopping center: apontamentos para a discussão da redefinição da centralidade em cidades médias. Porto Alegre, Revista GEOSUL, 2014 (processo de avaliação).

SOUSA, Marcos Timóteo Rodrigues. Logística Global. São Paulo: Unicid, 2013.

SOUSA, Marcos Timóteo Rodrigues. População e Ambiente: elementos demográficos na análise do território. São Paulo: Plêiade, 2006.

SOUZA, Marcelo L. Urbanização e desenvolvimento no Brasil Atual. São Paulo: Ática, 1996.

SPOSITO, Maria Encarnação Beltrão. Lógicas econômicas e práticas espaciais contemporâneas: cidades médias e consumo. 2011, 43f. Projeto Temático FAPESP (Geografia) - Universidade Estadual Paulista, Faculdade de Ciências e Tecnologia, Presidente Prudente.

SPOSITO, Maria Encarnação B. Globalização, consumo e papéis intermediários de cidades médias no Brasil. In: BELLET SANFELIU, Carmen Bellet; SPOSITO, Maria Encarnação Beltrão (Orgs). Las ciudades medias o intermédias en un mundo globalizado. Lleida: Universitat de Lleida, 2009. p. 41-69.

. "Cidades médias: reestruturação da cidade e reestruturação urbana". In: SPOSITO, Maria Encarnação B. (org.). Cidades médias: espaços em transição. SãoPaulo: Expressão Popular, 2007, p. 233-253.

VASCONCELOS, Eduardo Alcântara. Transporte urbano, espaço e equidade Análise das políticas públicas. São Paulo: Annablume, 2001.

VASCONCELOS, Eduardo Alcântara. Transporte urbano nos países em desenvolvimento: reflexões e propostas. São Paulo: Annablume, 2000.

VILLAÇA, Flávio. Uso do solo urbano. $1^{\text {a }}$ ed. São Paulo: Centro de Estudos e Pesquisas de Administração Municipal, 1978.

. Espaço intra-urbano no Brasil. São Paulo: Editora Studio Nobel, 2001.

WHITACKER, Arthur Magon. A produção do espaço urbano em Presidente 
Prudente: uma discussão sobre a centralidade urbana. Presidente Prudente: Faculdade de Ciências e Tecnologia. Universidade Estadual Paulista Júlio de Mesquita Filho, 1997. [Dissertação de mestrado].

ZANDONADI, Júlio Cesar. Cidades médias e cidades de médio porte: distinção a partir de situações geográficas interurbanas e dinâmicas da centralidade intraurbana - uma análise comparativa entre Taboão da Serra (SP), Marília (SP) e São Carlos (SP). Campinas, UNICAMP, Tese de Doutorado, 2013. 